\title{
Desenvolvimento de cerveja no estilo witbier adicionada de gengibre (Zingiber officinalis) e sua influência na fermentação
}

\section{Development of witbier with added ginger (Zingiber officinalis) and its influence on fermentation}

\author{
Barbara Reis Selvati Costa ${ }^{1 *}$, Yasmin da Silva Gomes ${ }^{1}$, Celestina Alexandrina Costa Cazuza $^{2}$, Luana \\ Tashima ${ }^{3}$, Lígia Marcondes Rodrigues dos Santos ${ }^{4}$
}

Como citar esse artigo. Costa, B.R.S.; Gomes, Y.S.; Cazuza, C.A.C.; Tashima, L.; dos Santos, L.M.R. Desenvolvimento de cerveja no estilo witbier adicionada de gengibre (Zingiber officinalis) e sua influência na fermentação. Revista Teccen. 2020 Jul./Dez.; 13 (2): 52-56.

\section{Resumo}

A cerveja é uma bebida fermentada composta por água, malte, lúpulo e levedura e cujos principais processos de fabricação são: moagem do malte, mosturação, fervura do mosto, fermentação e carbonatação. A witbier, estilo belga de alta fermentação, caracteriza-se por ter aroma e sabor refrescante, que também é característica sensorial do gengibre. Essa especiaria possui benefícios terapêuticos antimicrobianos que podem afetar o crescimento celular das leveduras (NICÁCIO et al, 2018). O objetivo do trabalho foi produzir uma cerveja do estilo witbier adicionada de gengibre na Cervejaria Escola da Universidade de Vassouras (Vassouras, RJ) e analisar o crescimento de células de levedura, o teor alcóolico e o extrato. Para a produção da cerveja, o gengibre foi adicionado na etapa de fervura. A fermentação foi conduzida em fermentadores de $15 \mathrm{~L}$ com as concentrações de gengibre iguais a $0,0,1,5$ e 3,0 g/L. Deste modo, foi observado que a adição de gengibre na cerveja retardou o crescimento celular, mas não o suficiente para impedir que todas fermentações chegassem ao mesmo patamar de extrato final, demonstrando que apesar das características antimicrobianas do gengibre, ele se mostrou uma matéria-prima capaz de ser utilizada para o estilo de cerveja produzido neste estudo.

Palavras-chave: : Witbier, Gengibre, Crescimento Celular.

\begin{abstract}
Beer is made from water, malt, hops and yeast and goes through malt grinding, mashing, wort boiling, fermentation and carbonation. Witbier, a top fermented style, presents itself by a refreshing aroma and flavor, which is also a ginger characteristic. This spice has therapeutic antimicrobial benefits that can affect yeast cell growth (NICÁCIO et al, 2018). The objective of the work was to produce a witbier style beer added with ginger at the Cervejaria Escola of the University of Vassouras (Vassouras, $\mathrm{RJ})$ and to analyze the growth of yeast cells, the alcohol content and the extract. For the production of beer, ginger was added at the boiling stage. Fermentation was carried out in $15 \mathrm{~L}$ fermenters with ginger concentrations equal to $0.0,1.5$ and $3.0 \mathrm{~g} / \mathrm{L}$. Thus, it was observed that the addition of ginger in beer slowed cell growth, but not enough to prevent all fermentations from reaching the same level of final extract, demonstrating that despite the antimicrobial characteristics of ginger, it proved to be a raw material able to be used for the style of beer produced in this study.
\end{abstract}

Keywords: Witbier, Ginger, Cell Growth.

\section{Introdução}

A produção da cerveja é uma das atividades mais antigas da humanidade e com o tempo a bebida alcoólica e seus processos tiveram uma grande evolução. A princípio os padeiros produziam bolos com grãos de cereais e levedura. Os bolos eram assados, desfeitos e armazenados em jarras com água para que ocorresse a fermentação (FLORES et al, 2015).

Atualmente, a cerveja é composta por água, malte, lúpulo e levedura, onde, segundo o Decreto 9.902/2019 e a Instrução Normativa $\mathrm{N}^{\circ} 65$, de 10 de Dezembro de 2019, o malte pode ser substituído parcialmente por adjunto cervejeiro (BRASIL, 2019; MAPA, 2019). O processo industrial segue as operações de moagem, mosturação, fervura do mosto cervejeiro, fermentação, maturação, carbonatação e envase (FLORES et al, 2015).

A cerveja é classificada em dois tipos de fermentação: alta fermentação e baixa fermentação. Conhecida como lagers, as de baixa fermentação ocorrem entre $7^{\circ} \mathrm{C}$ a $15^{\circ} \mathrm{C}$, durante 7 a 10 dias. E as cervejas de alta fermentação - ale - são fermentadas com temperaturas entre $18^{\circ} \mathrm{C}$ a $24^{\circ} \mathrm{C}$, durante 3 ou 4 dias (MARTINS \& FERREIRA, 2013).

O estilo de cerveja produzido neste estudo é do tipo belga, de alta fermentação, conhecida como Witbier. Segundo o guia de estilos BJCP (Beer Judge

Afiliação dos autores:

${ }^{1}$ Discente da Universidade de Vassouras, Vassouras, RJ, Brasil

${ }^{2}$ Bolsista Jovem Talentos FAPERJ da Universidade de Vassouras, Vassouras, RJ, Brasil

${ }^{3}$ Farmacêutica, Universidade de Vassouras, Vassouras, RJ, Brasil

${ }^{4}$ Docente da Universidade de Vassouras, Vassouras, RJ, Brasil

* Email de correspondência: barbaraselvati@outlook.com 
Certification Program) utilizado como guia internacional de classificação de estilos de cerveja, ela pode ser caracterizada pela aparência amarelo dourado, aroma maltado doce, frutado, cítrico e com leve fragrância de coentro (STRONG \& ENGLAND, 2015).

Tradicionalmente ela é produzida com trigo não maltado, malte claro (tipo Pilsen), levedura, semente de coentro e raspas de laranja que caracterizam o aroma e sabor refrescante do estilo. Pode-se adicionar também outras especiarias que se enquadram ao estilo cítrico e refrescante (STRONG \& ENGLAND, 2015).

Originário do sul da Ásia, o gengibre, conhecido por Zingiber officinale roscoe, possui benefícios terapêuticos como antimicrobiano, anti-inflamatório, antipirético, diurético e antioxidante. Ademais, atua como especiaria na culinária, onde entra na preparação de molhos, peixes e bebidas alcoólicas (NICÁCIO et al, 2018).

Menezes (2019) contrapôs a produção industrial em larga escala com a produção de duas microcervejarias artesanais, todas com produção da cerveja estilo do tipo Witbier. A comparação foi realizada entre o processo produtivo, as características físico-químicas e as propriedades antioxidantes. Considerando as análises obtidas, as cervejas artesanais atingiram um melhor resultado em relação às propriedades oxidantes, que estão associadas à composição da cerveja.

Tozetto et al (2019) produziu e caracterizou físicoquimicamente uma cerveja artesanal de gengibre. Após a produção, foram analisadas também 28 amostras de cerveja compradas no comércio local. Os resultados do álcool, extrato original, potássio e magnésio indicaram que a cerveja com gengibre demonstrou diferentes características.

Martins e Ferreira (2013) desenvolveram uma cerveja do tipo Pilsen com adição de gengibre, no qual foram realizadas análises físico-químicas e microbiológicas. Ademais, a adição do gengibre foi satisfatória para o trabalho porque houve uma redução de contaminantes presentes na biomassa através da contagem de colônias contendo o meio de cultura YMA (Yest Malt Agar). Entretanto, apenas os sólidos totais estiveram abaixo de $3,7^{\circ}$ Brix.

$\mathrm{O}$ gengibre foi escolhido como especiaria, por ter sabor pungente e aroma característico que se adequa ao estilo e por ter propriedades antioxidantes e antimicrobianas. Na literatura não foi possível encontrar a produção de cerveja do tipo witbier adicionada de gengibre, em vista disso, o trabalho tem como objetivo a sua produção e análise em relação ao teor de álcool, extrato, crescimento celular das leveduras e sensorial.

\section{Material e Métodos}

\section{Processo de Produção da Cerveja}

Para a realização do presente trabalho a cerveja do estilo Witbier adicionada de gengibre foi desenvolvida na Cervejaria Escola da Universidade de Vassouras (Vassouras, RJ) de acordo com a Figura 1. As matériasprimas estão contidas na Tabela 1 .

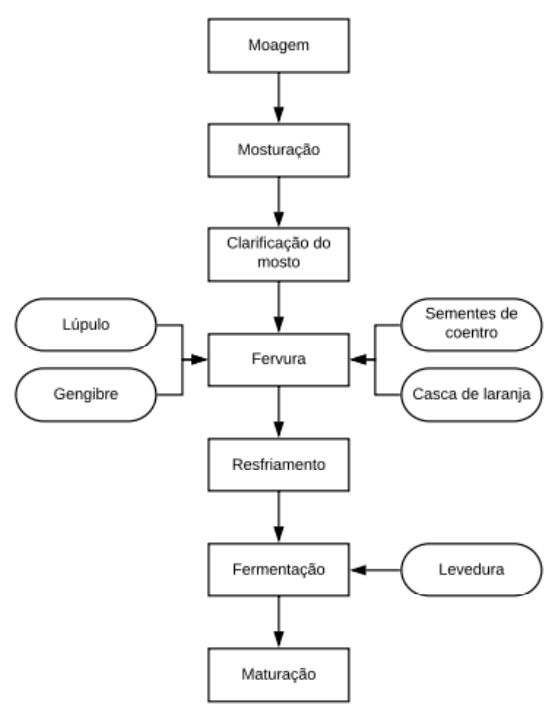

Figura 1. Fluxograma do processo realizado na Cervejaria Escola da Universidade de Vassouras

Acresce que foram utilizadas três concentrações diferentes do gengibre com o propósito de observar a influência no crescimento das leveduras. $\mathrm{O}$ estudo foi realizado em duplicata nas concentrações de $0,0,1,5 \mathrm{e}$ $3,0 \mathrm{~g} / \mathrm{L}$

Tabela 1. Matérias-primas utilizadas na produção de 70 litros de mosto que foram divididos em 6 fermentadores com 7,5 litros cada.

\begin{tabular}{|c|c|}
\hline \multicolumn{2}{|c|}{ Matérias-primas } \\
\hline Malte Pilsen & $13 \mathrm{~kg}$ \\
\hline Malte de Trigo & $2,5 \mathrm{~kg}$ \\
\hline Levedura Nottingham $\overline{\mathbb{R}}$ & $22,5 \mathrm{~g}$ \\
\hline Semente de coentro & $40 \mathrm{~g}$ \\
\hline Casca de laranja & $100 \mathrm{~g}$ \\
\hline Lúpulo Magnum(3) & $25 \mathrm{~g}$ \\
\hline
\end{tabular}

Primordialmente, o processo iniciou com a moagem de $13 \mathrm{~kg}$ de malte Pilsen e $2,5 \mathrm{~kg}$ de malte de Trigo. Logo após, na etapa de mosturação, o malte 
foi adicionado a 56 litros de água na temperatura de $45^{\circ} \mathrm{C}$. No tanque, o mosto foi aquecido com agitação em diferentes temperaturas de acordo com a Figura 2.

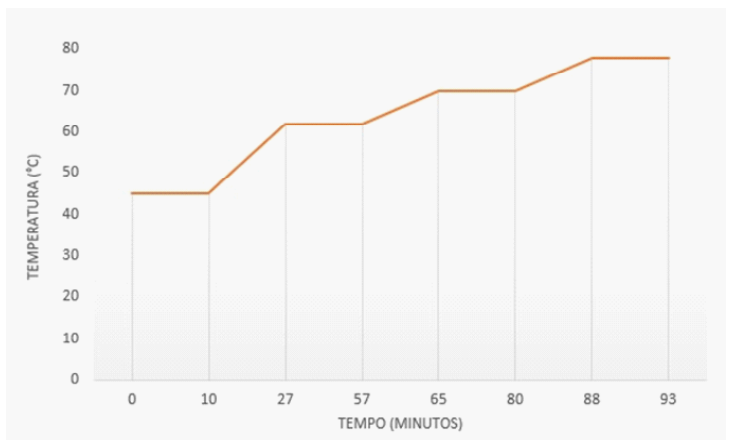

Figura 2. Rampa de temperatura utilizada na mostura da produção de cerveja estilo Witbier adicionada de gengibre.

Com o fim da mosturação, o mosto foi transferido para a tina de clarificação. $\mathrm{O}$ resíduo desta etapa (bagaço) foi destinado ao Hospital Veterinário da Universidade de Vassouras, Vassouras, RJ, com a finalidade de ser utilizado como ração para os animais de grande porte.

$\mathrm{Na}$ etapa de fervura, o mosto foi aquecido a $100{ }^{\circ} \mathrm{C}$ durante uma hora. Com 10 minutos da fervura o lúpulo Magnum ${ }^{\circledR}$ da marca $\mathrm{HVG}$ foi adicionado, para conferir o amargor da cerveja. Essa variedade apresenta características sensoriais florais e cítricas (Hieronymus, 2012). Não foi utilizado lúpulo de aroma, pois o objetivo era que o aroma da cerveja fosse proveniente do gengibre, especiarias e subprodutos da fermentação.

Aos 45 minutos foram adicionadas as sementes de coentro e as cascas da laranja no tanque de fervura. Ao mesmo tempo em uma manta aquecedora, foram fervidos $500 \mathrm{~mL}$ do mosto e as raspas de gengibre, nas concentrações de 1,5 e $3 \mathrm{~g} / \mathrm{L}$, respectivamente.

Com o fim da fervura, o mosto foi resfriado através de um trocador de calor de placas e transferido para os fermentadores com capacidade de $15 \mathrm{~L}$ que receberam 7,5 litros cada e foram adicionados de gengibre nas concentrações de $0,0,1,5$ e $3,0 \mathrm{~g} / \mathrm{L}$. As fermentações foram realizadas em duplicata.

Porúltimo, foi inoculada a Levedura Nottingham ${ }^{\circledR}$ seca, do tipo Saccharomyces cerevisiae, produzida pela empresa Lallemand. Essa levedura possui aromas e sabores ligeiramente frutados e neutros, com capacidade de fermentar uma grande variedade de estilos com alta performance (LALLEMAND BREWING, 2019). A fermentação durou 4 dias em temperatura entre 20 e $23^{\circ} \mathrm{C}$. Após o término da fermentação, deu-se início a maturação, que durou 10 dias na temperatura de $0^{\circ} \mathrm{C}$.

\section{Análises Físico-Químicas}

\section{Extrato}

Durante a produção do mosto, a concentração de extrato foi determinada através do refratômetro digital - Kasvi ( $\left.{ }^{\circ} \mathrm{Brix}\right)$, onde foram adicionadas 2 gotas do mosto resfriado. Para a análise diária, foi utilizado o sacarômetro segundo o método Analytica, E. B. C. (1998).

\section{Teor Alcoólico}

A análise de teor de álcool foi realizada de acordo com Métodos físico-químicos para análise de alimentos - Instituto Adolfo Lutz (2008).

\section{Crescimento Celular}

A contagem de células foi realizada através de uma câmara de Neubauer e diluições de 10,50 e 100 vezes de acordo com Brock et al (2010). Por fim foi utilizada a eEquação 1 para calcular o número de células por volume em mililitros.

$$
n^{\circ} \text { de } \frac{\text { células }}{m L}=\frac{n^{\circ} \text { total de células }}{n^{\circ} \text { de quadrantes contados }} \times \text { fator de diluição } \times 1000
$$

\section{Estatística}

O extrato, álcool e crescimento celular realizados em triplicata foram comparados através do teste de ANOVA e quando os resultados apresentaram $p<0,05$ foi aplicado o Teste de Tukey.

\section{Resultados e Discussão}

A análise do decaimento do extrato $\left({ }^{\circ} \mathrm{P}\right)$ durante a fermentação pode ser observada na Figura 3. Já no primeiro dia de fermentação foi possível observar a queda do extrato que se inicia com $11^{\circ} \mathrm{P}$ e após quatro dias terminou com 1,5 ${ }^{\circ}$ P. De acordo com Strong e England (2015), o extrato original de uma cerveja witbier deve ficar entre 11 e $13^{\circ} \mathrm{P}$ e o extrato aparente final entre $2 \mathrm{e}$ $3^{\circ} \mathrm{P}$. Não houve diferença significativa (P. 0,05$)$ entre os valores de extrato para todas as análises.

De acordo com Wolfgang (2014), extrato original corresponde ao teor de sólidos solúveis, sendo rico em açúcares fermentescíveis e não fermentescíveis. Já o extrato aparente final representa o teor de sólidos solúveis após a fermentação considerando a influência do álcool, uma vez que a análise é feita através da densidade e o álcool possui uma densidade mais baixa 
do que a água.

$\mathrm{O}$ decaimento de extrato da amostra com $3 \mathrm{~g} / \mathrm{L}$ de gengibre foi mais lento que as outras duas amostras, entretanto as 3 amostras chegaram no mesmo valor, no entanto ficou abaixo do preconizado por Strong e England (2015). Esse comportamento demonstra que o gengibre na concentração mais alta pode ter influenciado a performance da fermentação, já que o mesmo não pode ser observado com a concentração de $1,5 \mathrm{~g} / \mathrm{L}$.

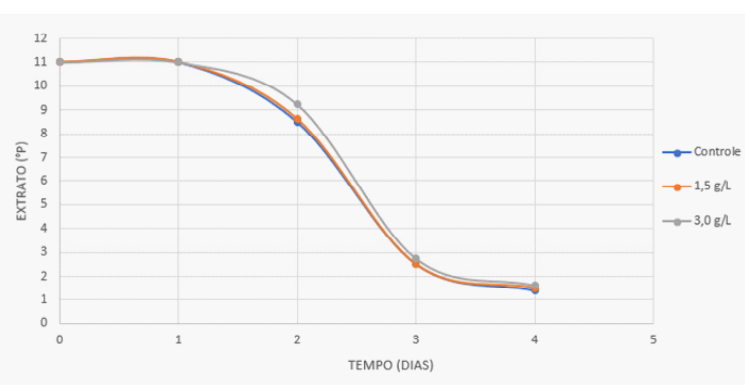

Figura 3. Decaimento do extrato $\left({ }^{\circ} \mathrm{P}\right)$ durante 4 dias de fermentação. A linha azul corresponde a cerveja sem adição de gengibre $(0,0 \mathrm{~g} / \mathrm{L})$, a linha laranja corresponde a cerveja com $1,5 \mathrm{~g} / \mathrm{L}$ e a cinza $3,0 \mathrm{~g} / \mathrm{L}$ de gengibre.

$\mathrm{O}$ resultado aparente final mais baixo se deve provavelmente a atividade enzimática das amilases mais intensa, onde há maior formação de açúcares fermentescíveis.

Nos estudos de Matsubara e Plath (2014) e Martins e Ferreira (2013) sobre cervejas com adição de gengibre também não houve diferença no extrato aparente final alcançado após a fermentação, indicando que o gengibre não impede a atividade da levedura.

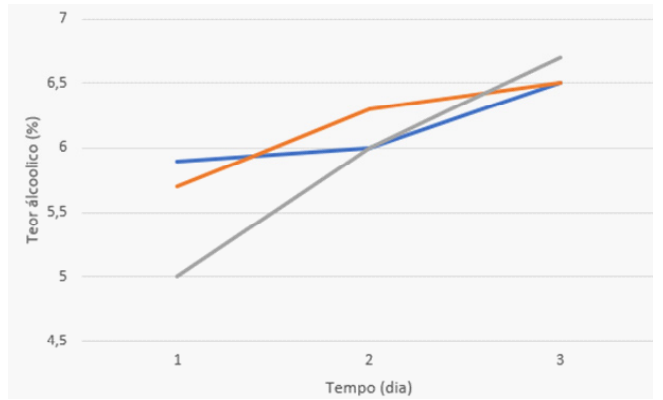

Figura 4. Teor alcóolico $(\% \mathrm{v} / \mathrm{v})$. A linha azul corresponde a cerveja sem adição de gengibre $(0,0$ $\mathrm{g} / \mathrm{L})$, a linha laranja corresponde a cerveja com 1,5 $\mathrm{g} / \mathrm{L}$ e a cinza $3,0 \mathrm{~g} / \mathrm{L}$ de gengibre.

A análise de teor alcóolico foi realizada durante os três últimos dias de fermentação e os valores encontrados estão retratados na Figura 4. Segundo Strong e England (2015) os resultados encontrados não estão dentro do valor padrão para o estilo estudado pois o máximo por este guia é de $5,5 \%(\mathrm{v} / \mathrm{v})$ e neste estudo as amostras ficaram entre 6,5 e $6,7 \%(\mathrm{v} / \mathrm{v})$ e não houve diferença significativa $(\mathrm{P}>0,05)$ entre elas. Pode-se ressaltar que nem a amostra controle apresentou valores dentro do padrão segundo Strong e England (2015), isso é decorrente da atividade enzimática das amilases na etapa de mostura. Matsubara e Plath (2014) ao desenvolver uma cerveja artesanal de trigo adicionada de gengibre também não observou alteração no teor alcoólico na presença de gengibre de até $1 \%$ de gengibre.

A Figura 5 representa o crescimento celular da leveduraSaccharomycescerevisiae durante os quatrodias de fermentação, onde comparamos o comportamento da levedura na amostra controle $(0,0 \mathrm{~g} / \mathrm{L})$ com as amostras contendo gengibre nas concentrações de $1,5 \mathrm{~g} / \mathrm{L}$ e 3 $\mathrm{g} / \mathrm{L}$.

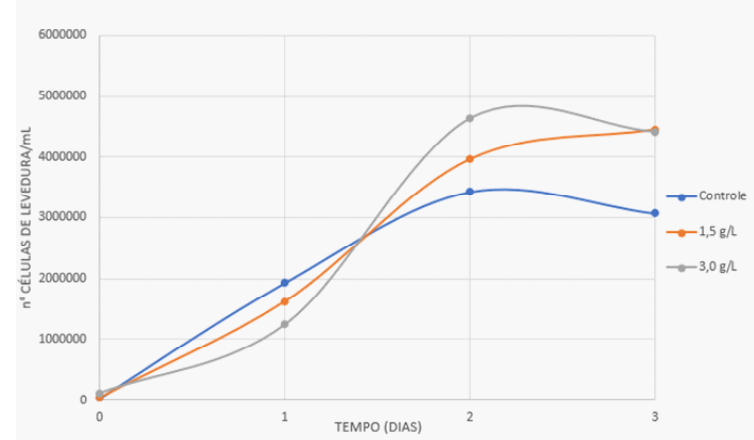

Figura 5. Crescimento celular da levedura Saccharomyces cerevisiae na amostra controle e na presença de gengibre. A linha azul corresponde a cerveja sem adição de gengibre $(0,0 \mathrm{~g} / \mathrm{L})$, a linha laranja corresponde a cerveja com $1,5 \mathrm{~g} / \mathrm{L}$ e a cinza $3,0 \mathrm{~g} / \mathrm{L}$ de gengibre.

Observa-se que na fase lag o crescimento celular da amostra controle é maior o que é uma indicação de que há uma inibição do crescimento celular devido a presença do gengibre nas outras amostras. Essa inibição pode estar relacionada com a propriedade antifúngica, do gengibre, afetando diretamente a levedura (BROCK et al, 2010).

Ou seja, apesar de começar mais lentamente, a amostra com adição de $3,0 \mathrm{~g} / \mathrm{L}$ de gengibre teve um crescimento exponencial mais acelerado e atingiu, ao final da fermentação, um número de células $30 \%$ maior do que a amostra controle. O mesmo também aconteceu para a amostra com adição de $1,5 \mathrm{~g} / \mathrm{L}$ que apresentou $31 \%$ a mais de células do que a amostra controle, onde não houve adição de gengibre. Houve diferença significativa $(\mathrm{P}<0,05)$ somente no primeiro dia de crescimento e assim foi possível observar que possivelmente o gengibre aumentou a fase lag das amostras que tiveram a sua adição, mas sua ação antifúngica não foi expressiva e ele não afetou o crescimento celular a partir da fase exponencial de crescimento.

Esse crescimento mais elevado das amostras com gengibre comparadas com a amostra controle 
também foi verificado por Diakabana et al (2019) possivelmente porque a inibição do crescimento pelo gengibre se restrinja somente à fase lag e depois ele acaba funcionando como um ativador do crescimento.

\section{Considerações Finais}

Os processos e receitas para a produção da cerveja artesanal vem sendo inovados a todo momento. Com isso, ao produzir uma cerveja no estilo Witbier o gengibre foi adicionado com intuito de obter um produto com boa aceitabilidade sensorial. Neste estudo foi possível analisar a atividade de uma levedura de alta fermentação durante esta etapa na presença de gengibre nas concentrações de 1,5 e 3,0 g/L e compará-las a uma amostra controle onde não houve adição.

Tanto nas análises de decaimento de extrato como na produção de álcool e crescimento celular, foi visto que o gengibre atrasa o processo de fermentação, em especial na concentração de $3,0 \mathrm{~g} / \mathrm{L}$, mas não prejudica o resultado final de todas as análises, uma vez que todas as amostras atingiram um resultado final próximo.

\section{Referências}

Analytica, E. B. C. (1998). European brewery convention. Grundwerk: Section, 7.

BRASIL. Decreto n. 9.902, de 8 de jul. de 2019. Dispõe sobre a padronização, a classificação, o registro, a inspeção, a produção e a fiscalização de bebidas. Brasília, DF, 2019. Disponível em: <http://www.planalto.gov.br/ccivil_03/ Ato2019-2022/2019/Decreto/D9902.htm>. Acesso em: 10 de fev. de 2020.

Brock, T., Madigan, M., Martinho, J., \& Parker, J. (2010). Microbiologia de Brock.

Flores, A. B., Gräff, A., Cornelius, E., \& de Souza, C. F. V. (2015). Perfil sensorial e avaliações físico-químicas de cerveja artesanal de chocolate e caramelo. Revista Destaques Acadêmicos, 7(4).

Diakabana, P., Dzondo, M. G., Tamba Sompila, A. W. C., Moussounga, J. E., Ntsossani, S. P., Kobawila, S. C., \& Louembé, D. (2019). Optimization of The Process of Production of Brandy from Sweetened Juice of Pulp of Ginger (Zingiber officinale Roscoe) Using Saccharomyces Cerevisiae Yeast at Brazzaville. Indian Journal of Research in Pharmacy and Biotechnology (IJRPB), 7(3).

Hieronymus, S. (2012). For the love of hops: The practical guide to aroma, bitterness and the culture of hops. Brewers publications.

IAL-Instituto Adolfo Lutz. (2008). Normas Analíticas do Instituto Adolfo Lutz. Métodos físico-químicos para análise de alimentos.

LALLEMAND BREWING. (2019). Nottingham High Performance Ale Yeast. Disponível em:< https:/www.lallemandbrewing.com/docs/products/ tds/TDS LALBREW_PREM_NOTTINGHAM_ENGLISH_DIGITAL. pdf $>$. Acesso em: 22 de nov. de 2020.

MAPA - Ministério da Agricultura, Pecuária e Abastecimento. (2019). Instrução Normativa $n^{\circ} 65$, de 10 de dez. de 2019. Estabelece os padrões de identidade e qualidade para os produtos de cervejaria. Disponível em: $<$ https://www.in.gov.br/en/web/dou/-/instrucao-normativa-n-65-de-10-dedezembro-de-2019-232666262>. Acesso em : 22 de nov. de 2020.

Martins, P. K. B., \& Ferreira, V. S. (2013). Produção de cerveja artesanal com gengibre (Zingiber officinalis) (Bachelor's thesis, Universidade Tecnológica Federal do Paraná)

Matsubara, A. K., \& Plath, A. R. (2014). Desenvolvimento de cerveja artesanal de trigo adicionada de gengibre (Zingiber Officinale Roscoe) (Bachelor's thesis, Universidade Tecnológica Federal do Paraná).

Menezes, M. F. T. D. (2019). Estudo comparativo entre cervejas Witbier: processo produtivo, aspectos físico-químicos e bioquímicos (Bachelor's thesis, Universidade Federal do Rio Grande do Norte).

Nicácio, G. L., Moura, S., Costa, J. V. D. J., Sena, C. R., Cruz, T. B., Lopes, G. N., \& Cecilio, A. B. (2018). BREVE REVISÃO SOBRE AS PROPRIEDADES FITOTERÁPICAS DO ZINGIBER OFFICINALE-O GENGIBRE. Sinapse Múltipla, 7(2), 74-80.

Strong, G., \& England, K. (2015). Beer Judge Certification Program: 2015 style guidelines. Acesso em, 3.

Tozetto, L. M., NASCIMENTO, R. F. D., OLIVEIRA, M. H. D., Van Beik, J., \& CANTERI, M. H. G. (2019). Production and physicochemical characterization of craft beer with ginger (Zingiber officinale). Food Science and Technology, 39(4), 962-970.

Wolfgang, K. (1996). Technology brewing and malting. YEAST", VLB, 7583 . 